\title{
O PACTO DE SAN JOSÉ DA COSTA RICA E A JURISPRUDÊNCIA INTERAMERICANA EM MATÉRIA DE DIREITO À SAÚDE
}

\author{
PACT OF SAN JOSE, COSTA RICA AND THE INTER-AMERICAN \\ JURISPRUDENCE ABOUT RIGHT TO HEALTH \\ Flavia Piovesan ${ }^{1}$ \\ Daniel Castanha de Freitas ${ }^{1}$
}

\begin{abstract}
Recebido em: 08/05/2018 Aceito em: 07/06/2018

flaviapiovesan@terra.com.br advcastanha@gmail.com
\end{abstract}

Resumo: O artigo analisa a jurisprudência interamericana em matéria de direito à saúde, com destaque aos casos julgados pela Comissão e Corte Interamericanas. Discorre-se acerca do sistema de proteção multinível dos direitos humanos, enfatizando sua importância para o estabelecimento de um arcabouço normativo plural quanto à sua origem, porém uníssono em relação aos objetivos perseguidos. Em seguida, aborda-se o impacto das decisões proferidas pela Corte Interamericana de Direitos Humanos no ordenamento jurídico brasileiro, em razão de sua submissão aos termos da Convenção Americana de Direitos Humanos de 1969. Finalmente, empreende-se estudo da jurisprudência da Corte e Comissão Interamericana de Direitos Humanos, permitindo-se sustentar a gradativa pavimentação de um constitucionalismo regional - ius commune social -, bem como a emergência de um Estado de Direito Internacional, pautado pelo primado da legalidade, por uma expansiva institucionalidade baseada em instrumentos e órgãos internacionais visando à dignidade humana, com ênfase na proteção dos direitos dos mais vulneráveis.

Palavras-chave: Convenção Americana de Direitos Humanos. Corte Interamericana de Direitos Humanos. Comissão Interamericana de Direitos Humanos. Direitos humanos. Direito à saúde.

\begin{abstract}
This study analyzes the inter-American jurisprudence on the right to health, especially in cases judged by the Commission and the Inter-American Court. It talks about multilevel protection system of human rights, emphasizing it importance for establishing a plural normative framework as to its origin, but unison in relation to the objectives pursued. Then discusses the impact of judgments by the Inter-American Court of Human Rights in the Brazilian legal system, due to it submission to the terms of the American Convention on Human Rights, 1969. Finally, undertakes to study the Court's jurisprudence and the InterAmerican Commission on Human Rights, respectively, allowing sustain gradual paving of a regional constitucionalism - social ius commune -, and the emergence of an International Rule of Law, guided by legality, by an expansive institutions based on international instruments and bodies that aimed the human dignity, whith an emphasis on protecting the rights of the most vulnerable.
\end{abstract}

Keywords: American Convention of Human Rights. Inter-American Court of Human Rights. Inter-American Commission of Human Rights. Human rights. Right to health.

\section{INTRODUÇÃO}

Fruto do amadurecimento das sociedades contemporâneas, por sua vez impulsionadas pela necessidade de superação das mazelas da Segunda Grande Guerra, a noção contemporânea do direito internacional dos direitos humanos surgiu como instrumento de efetivação da dignidade da pessoa humana, atingindo indistintamente aqueles que reúnem apenas e tão somente uma característica em comum: a condição de pessoa.

\footnotetext{
${ }^{1}$ Pontifícia Universidade Católica do Paraná - PUCPR - Curitiba - Paraná - Brasil
} 
Suas notáveis premissas abarcam uma ampla gama de direitos civis, políticos, sociais, econômicos e culturais, os quais se revelam indissociáveis, mesmo porque considerados indivisíveis, interdependentes e inter-relacionados, verdadeira construção normativa em favor da plenitude do livre-arbítrio.

Afinal, é certo que, com a promulgação da Constituição da República Federativa do Brasil de 1988, ampliou-se significativamente o leque de direitos sociais a partir da incorporação de diversas disposições protetivas de direitos humanos, consolidando a salvaguarda de direitos concernentes ao regime democrático amadurecido após o fim do período ditatorial (1964-1985).

Inclusive, a título de exemplo, rememore-se a receptiva previsão contida no parágrafo terceiro do art. 5o da Constituição da República, segundo a qual os tratados e convenções internacionais sobre direitos humanos, aprovados na forma especificada, possuem status de emenda constitucional, fato que prestigia o diálogo entre o direito interno e o internacional e demonstra sintonia entre ambos os sistemas normativos.

Para além da implementação espontânea do direito à saúde realizada pelo Estado-membro brasileiro, a qual se dá por meio de políticas públicas destinadas a garantir o cumprimento dos éditos nacionais e supranacionais e que visam à promoção da universalidade almejada (art. 196 da Constituição), a atuação do Judiciário, é tida como importante método complementar de consagração deste direito fundamental social.

É por meio da judicialização de pedidos de medicamentos, tratamentos e intervenções cirúrgicas, suplementos alimentares, próteses e órteses, que se reafirma o real alcance das disposições humanitárias referidas tanto na Convenção Americana de Direitos Humanos adotada em 1969 (também denominada Pacto de San José da Costa Rica), em vigor desde 1978, após o depósito do $11^{\underline{a}}$ instrumento de ratificação, quanto no Protocolo de San Salvador, concebido em 1998 e em vigor desde 1999, nos mesmos termos.

Por outro lado, a identidade de valores humanitários encontrada no Texto Fundamental nacional e nos escritos supranacionais decorrentes da vontade dos Estados americanos signatários da Convenção Americana de Direitos Humanos e Protocolo de San Salvador evidencia a existência de um sistema de proteção multinível dos direitos humanos, capaz de amparar, por exemplo, a prerrogativa do direito à saúde em várias dimensões, no âmbito local, nacional e regional.

A partir de tal horizonte, é possível entender que o Poder Judiciário brasileiro, ao proferir decisões, assume o dever inderrogável de observar, a um só tempo, os enfoques trazidos por ambas as construções normativas, como forma de reverenciar o diálogo jurisdicional e atender aos princípios inerentes aos parâmetros de proteção mínimos de seus titulares.

A aludida proteção dos direitos humanos igualmente permite que os julgamentos sejam submetidos a monitoramento, sendo previstos dois órgãos de proteção na Convenção Americana de Direitos Humanos, quais sejam a Comissão Interamericana de Direitos Humanos e a Corte 
Interamericana de Direitos Humanos, cada qual com atribuições específicas, garantindo-se, com isso, a devida accountability do Estado-membro em questão por meio de relatórios, petições, queixas etc.

Tanto a Comissão, quanto a Corte Interamericana de Direitos Humanos, exararam relevante jurisprudência em casos que envolviam o direito à saúde e sua efetividade perante um dos Estadosmembros, inclusive no Brasil, ainda que de maneira indireta.

Tais leading cases conformam um "corpus juris interamericano" acerca do direito social à saúde, sem olvidar de argumentos que servem de supedâneo para o estabelecimento de parâmetros à melhoria do serviço de saúde como um todo.

O propósito do estudo, portanto, está em analisar o alcance e o impacto da jurisprudência interamericana em matéria de direito à saúde, fomentada pela Corte e Comissão Interamericana de Direitos Humanos. A pavimentação deste "corpus juris interamericano" aponta à importância da consolidação de um constitucionalismo regional transformador, em prol dos mais vulneráveis.

\section{A CONVENÇÃO AMERICANA DE DIREITOS HUMANOS - CADH}

Preliminarmente, importa esclarecer que não serão tecidas maiores considerações a respeito da gênese das relações internacionais havidas entre os Estados americanos ainda durante o século XIX, quando foi estabelecido o "International Union of American Republics", composto por 18 países e tido como o embrião da Organização dos Estados Americanos - OEA, responsável pela Convenção objeto de estudo (QUIROGA, 1988, p. 21).

Em relação ao momento histórico em que foi concebida a $\mathrm{CADH}$, cabe aqui rememorar as tensões que marcaram o período, em razão do elevado número de países latino-americanos que, à época, estavam subjugados por governos ditatoriais (PASQUALUCCI, 2003, p. 7) comumente caracterizados pela repressão a quaisquer reivindicações em prol dos direitos humanos. ${ }^{2}$

Ainda hoje é possível verificar países latinos que enfrentam processos de transição de regimes totalitários de esquerda ou direita para o democrático, o que faz transparecer o desafio dos Estados-membros vinculados à CADH de "romper em definitivo com o legado da cultura autoritária ditatorial e consolidar o regime democrático, com o pleno respeito aos direitos humanos, amplamente considerados" (PIOVESAN, 2014, p. 134).

Dessa forma, concebida com o propósito de vincular as nações integrantes da Organização dos Estados Americanos - $\mathrm{OEA}^{3}$ às prerrogativas de direitos humanos, a Convenção Americana de

\footnotetext{
${ }^{2}$ Sobre o assunto, recomenda-se a leitura de: QUIROGA, 1988. p. 1-32.

${ }^{3}$ Acerca da normatização bipartite que regula a OEA, digno de menção o comentário de HansJoachim Heintze, no seguinte sentido: "A Organização dos Estados Americanos (OEA), fundada em 1948, organização regional, segundo o capítulo VII da Carta da ONU, da qual 35 países fazem parte, criou seu próprio sistema de direitos humanos. Esse sistema consiste de duas bases legais
} 
Direitos Humanos - CADH, assinada inicialmente em 1969 e em vigor somente em 1978, por ocasião do depósito do $11^{\circ}$ instrumento de ratificação, representa o diploma normativo de maior significado para aqueles Estados-membros que dele compartilham (PIOVESAN, 2013, p. 331-332).

O Pacto de San José da Costa Rica, como é também referida a CADH, preconiza direitos de toda ordem em favor das pessoas, a exemplo dos direitos à vida (art. 4), à propriedade privada (art. 21), à proteção judicial (art. 25), à liberdade de pensamento e de expressão (art. 13), à proteção da família (art. 17), ao nome (art. 18), dentre tantas outras garantias previstas em seus 82 artigos (ORGANIZACIÓN DE LOS ESTADOS AMERICANOS, 1969).

Visto sob outro aspecto, observação pertinente está relacionada ao fato de que, muito embora seja frequentemente utilizada como fundamento para demandas que envolvam direitos sociais carentes de ações afirmativas, a Convenção, em verdade, dedicou inicialmente aos direitos econômicos, sociais e culturais - DESC - tão somente uma menção em cláusula normativa, constante do art. 26, intitulada de "desenvolvimento progressivo", cujos termos são os seguintes, in verbis:

\section{CAPÍTULO III \\ DIREITOS ECONÔMICOS, SOCIAIS E CULTURAIS}

Artigo 26. Desenvolvimento progressivo

Os Estados Partes comprometem-se a adotar providências, tanto no âmbito interno como mediante cooperação internacional, especialmente econômica e técnica, a fim de conseguir progressivamente a plena efetividade dos direitos que decorrem das normas econômicas, sociais e sobre educação, ciência e cultura, constantes da Carta da Organização dos Estados Americanos, reformada pelo Protocolo de Buenos Aires, na medida dos recursos disponíveis, por via legislativa ou por outros meios apropriados. (COMISSÃO INTERAMERICANA DE DIREITOS HUMANOS, 1969)

Entretanto, frise-se que a existência do artigo supramencionado foi - e continua sendo suficiente para fundamentar pretensões relacionadas ao direito à saúde, embora posteriormente, já em 1988, tenha sido confeccionado o instrumento denominado de Protocolo de San Salvador, em vigor a partir de 16 novembro de 1999, nos mesmo termos do documento anterior, que previu expressamente uma série de direitos sociais, inclusive à saúde, por meio do art. 10 (COMISSÃO INTERAMERICANA DE DIREITOS HUMANOS, 1969). Atualmente, 15 países ratificaram seus termos, dentre os quais o Brasil, havendo ressalva pelo Estado mexicano quanto aos direitos sindicais previstos no art. 8 (COMISSÃO INTERAMERICANA DE DIREITOS HUMANOS, 1969).

principais: a Carta da OEA e a Convenção Americana de Direitos Humanos." (HEINTZE, 2010, p. 2283)

Revista do Direito [ISSN 1982-9957]. Santa Cruz do Sul, v. 1, n. 54, p. 205-225, jan./abr. 2018. https://online.unisc.br/seer/index.php/direito/index 
Fábio Konder Comparato (2013, p. 379) sustenta que o fato de a Convenção não conter maiores disposições sobre os direitos econômicos, sociais e culturais se consubstanciou em uma manobra política dos conferentes na tentativa de atrair a adesão dos Estados Unidos da América, sendo este o motivo para a edição do Protocolo de San Salvador anos depois da vigência da Convenção.

Ato contínuo, tendo em vista o sólido arquétipo formado pelo Pacto de San José da Costa Rica, complementado pelo Protocolo de San Salvador, mister se faz ressaltar que a sua exigibilidade pelos cidadãos é imediata em face do Estado brasileiro, devendo haver estrita observância de seus preceitos pelo órgão jurisdicional no momento de sua aplicação.

Aliás, para além de garantir em seu âmbito de jurisdição o livre exercício daqueles direitos plasmados em ambos os instrumentos dantes mencionados, o Brasil e os demais subscritores da $\mathrm{CADH}$ detêm a incumbência de proporcionar ambiente favorável à confecção de legislação suficiente à efetiva implementação das garantias insculpidas na Convenção e no Protocolo, caso ainda inexistente ou despida de vigência. ${ }^{4}$

Há a responsabilidade estatal em adotar todas as medidas legislativas e de outra natureza que sejam necessárias para conferir efetividade aos direitos e liberdades enunciados (PIOVESAN, 2014, p. 137-138), assentando, a um só tempo, o caráter negativo da atitude estatal quanto aos direitos individuais, bem como sua postura positiva evidenciada pelas ações positivas que assegurem a salvaguarda de todos os direitos previstos na CADH.

Compreendido o contexto em que se insere a Convenção Americana de Direitos Humanos e as prerrogativas que confere aos cidadãos que integram os Estados-membros signatários de seus termos, importa destacar, valendo-se dos ensinamentos de Gilda Maciel Corrêa Meyer Russomano (2001, p. 45), que o reconhecimento dos direitos humanos de nada adianta sem que haja sua proteção efetiva.

Portanto, transita-se à análise de casos concretos que envolvem direitos humanos, consistentes em conflitos submetido aos dois órgãos de controle previstos na $\mathrm{CADH}$, quais sejam a Comissão Interamericana de Direitos Humanos e a Corte Interamericana de Direitos Humanos.

\footnotetext{
${ }^{4}$ Trata-se do art. 2 da CADH, redigido nos termos seguintes: "Si el ejercicio de los derechos y libertades mencionados en el artículo 1 no estuviere ya garantizado por disposiciones legislativas 0 de otro carácter, los Estados Partes se comprometen a adoptar, con arreglo a sus procedimientos constitucionales y a las disposiciones de esta Convención, las medidas legislativas o de otro carácter que fueren necesarias para hacer efectivos tales derechos y libertades." (ORGANIZACIÓN DE LOS ESTADOS AMERICANOS. Convención americana sobre derechos humanos suscrita en la conferencia especializada interamericana sobre derechos humanos. Disponível em: $<\mathrm{http}: / / \mathrm{www}$.oas.org/dil/esp/tratados_B-32_Convencion_Americana_sobre_Derechos_Humanos.pdf $>$. Acesso em: 19 jan. 2016.)
} 


\subsection{A Comissão Interamericana de Direitos Humanos}

A referência à Comissão Interamericana de Direitos Humanos constante do art. 33 da Convenção retrata, em verdade, uma ampliação em seu leque de atribuições, ocorrida em momento posterior à sua constituição.

Isso porque a Comissão "foi criada por resolução da Quinta Reunião de Consulta dos Ministros das Relações Exteriores em Santiago, Chile, em 1959. A CIDH foi formalmente instalada em 1960, quando o Conselho da Organização aprovou seu Estatuto", sendo "um dos órgãos do Sistema Interamericano responsáveis pela promoção e pela proteção dos direitos humanos" (ORGANIZAÇÃO DOS ESTADOS AMERICANOS, 2013).

Com a maximização de seu campo de atuação conferida pelos termos da Convenção, portanto, a Comissão Interamericana de Direitos Humanos possui competência para atuar não somente nos casos que envolvem os signatários da Convenção Americana sobre Direitos Humanos, como também as nações que integram o bloco da Organização dos Estados Americanos, sob a égide da Declaração Universal dos Direitos Humanos, aprovada pela Assembleia Geral das Nações Unidas em 10 de dezembro de 1948 e, atualmente, reconhecida e respeitada como instrumento detentor de força vinculante nos Estados-membros, independentemente de previsão constitucional interna (COMPARATO, 2013, p. 237-246). Essa é a razão de ser do art. 35 da CADH (ORGANIZACIÓN DE LOS ESTADO AMERICANOS, 1969).

Nos termos do art. 34 da CADH, por sua vez, está enunciado que a Comissão será composta por 7 (sete) membros, as quais "deverão ser pessoas de alta autoridade moral e de reconhecido saber em matéria de direitos humanos". Os arts. 36 e 37 indicam a maneira pela qual serão eleitos os Conselheiros, atentando ao fato de que os candidatos devem ser originários de qualquer dos Estados integrantes da OEA, bem como que o mandato é de 4 anos, sem olvidar da permissão de recondução única ao cargo.

A principal missão da Comissão é a salvaguarda dos direitos humanos previstos na Convenção Americana de Direitos Humanos. Para fins didáticos, reputa-se de grande valia transcrever os ensinamentos do art. 41 da $\mathrm{CADH}$ - verbis:

A Comissão tem a função principal de promover a observância e a defesa dos direitos humanos e, no exercício do seu mandato, tem as seguintes funções e atribuições: a) estimular a consciência dos direitos humanos nos povos da América; b) formular recomendações aos governos dos Estados membros, quando o considerar conveniente, no sentido de que adotem medidas progressivas em prol dos direitos humanos no âmbito de suas leis internas e seus preceitos constitucionais, bem como disposições apropriadas para promover o devido respeito a esses direitos; c) preparar os estudos ou relatórios que considerar convenientes para o desempenho de suas funções; d) solicitar aos governos dos Estados membros que Ihe proporcionem informações sobre as medidas que adotarem em matéria de direitos humanos; e) atender às consultas que, por meio da Secretaria-Geral da Organização dos Estados Americanos, Ihe formularem os Estados membros sobre questões relacionadas com os direitos 
humanos e, dentro de suas possibilidades, prestar-Ihes o assessoramento que eles Ihe solicitarem; f) atuar com respeito às petições e outras comunicações, no exercício de sua autoridade, de conformidade com o disposto nos artigos $44^{\circ}$ a $51^{\circ}$ desta Convenção; e g) apresentar um relatório anual à Assembléia Geral da Organização dos Estados Americanos (COMISSÃO INTERAMERICANA DE DIREITOS HUMANOS, 1969).

Dentre as tantas incumbências de grande relevo conferidas à Comissão, destaca-se aquela insculpida na alínea "f" supramencionada, vez que, conjugada com o art. 44 do mesmo diploma, possibilita a submissão, individual ou coletivo, por particulares ou mesmo ONG's, de denúncia de violação a direito previsto pela Convenção à Comissão Interamericana de Direitos Humanos. A respeito, estabelece a Convenção em seu artigo 44: "Qualquer pessoa ou grupo de pessoas, ou entidade não-governamental legalmente reconhecida em um ou mais Estados membros da Organização, pode apresentar à Comissão petições que contenham denúncias ou queixas de violação desta Convenção por um Estado Parte" (COMISSÃO INTERAMERICANA DE DIREITOS HUMANOS, 1969).

O Estado, ao se tornar parte da Convenção, aceita automática e obrigatoriamente a competência da Comissão para examinar essas comunicações, não sendo necessário elaborar qualquer declaração expressa e específica para tal fim (PIOVESAN, 2014, p. 141).

Sob um outro prisma, é certo que a petição dirigida à Comissão, para ser admitida e apreciada, deve respeitar certos pressupostos de admissibilidade.

Estes, por sua vez, estão previstos no art. 46 da CADH, podendo ser resumidos nos critérios de: a) esgotamento prévio de todos os modelos recursais previstos na legislação interna; b) protocolo da petição perante a Comissão dentro do prazo decadencial de 6 (seis) meses, contados a partir da notificação da decisão judicial definitiva; c) inexistência de outro processo submetido a jurisdição internacional para o caso a ser objeto de análise pela Comissão (espécie de litispendência); e d) qualificação e assinatura do requerente no pedido de providências dirigido à Comissão.

Apenas a título de esclarecimento, tem-se que os critérios previstos nas alíneas "a" e "b" serão mitigados segundo o caso concreto, quando há, v. g., casos de inexistência de contraditório ou demora proposital para a prolação de decisão. ${ }^{5}$

Ultrapassada a análise admissional pelo relator designado na Comissão, dá-se lugar ao contraditório, este evidenciado pelos procedimentos constantes dos arts. 48 a 51 da CADH.

Exemplos das condutas descritas nos artigos aludidos são: (i) a solicitação de informações ao Estado-membro denunciado (art. 48, 1, "a"); (ii) de posse das informações ou cientes da conduta negligente do Estado, deliberação posterior sobre o fato trazido à Comissão (art. 48, 1, "b"); (iii) arquivamento do feito, em caso de inexistência ou insubsistência dos fatos (art. 48, 1, "b"), ou ainda,

\footnotetext{
${ }^{5}$ Art. 46, inciso 2, "a", "b" e "c", da CADH. Sobre o assunto, vide: PIOVESAN, 2014, p. 142.
} 
exame detido das alegações, com investigação in loco, se reputado necessário (art. 48, 1, "d"); (iv) posterior tentativa conciliatória, realizada após a apuração do item anterior, com redação de relatório, caso frutífera, encaminhado às partes e aos demais Estados-membros da $C A D H$, publicado posteriormente no âmbito da OEA (art. 49); ( $v$ ) caso a conciliação reste infrutífera, elaboração de relatório final, de caráter vinculativo, contendo os fatos, conclusões, formulação de propostas e recomendações que entender adequadas, encaminhando-o aos Estados interessados, que não poderão publicá-lo (art. 50).

Da data em que for notificado do relatório final confeccionado pela Comissão, tem o Estado interessado o prazo de 3 (três) meses para dar cumprimento às prescrições formuladas por aquele órgão.

Não resolvida a questão, poderá a Comissão, desde que por maioria absoluta de votos de seus membros, emitir sua própria opinião e conclusão, fixando prazo para cumprimento e deliberando ao final dele acerca do cumprimento das prescrições (art. 51, 1).

Outra solução é a remessa do caso pela Comissão à Corte Interamericana de Direitos Humanos, responsável pelos julgamentos do sistema interamericano e que somente pode ser acessada por meio de provocação advinda da Comissão Interamericana ou dos Estados-membros (art. 61, 1).

Ademais, para que a submissão do caso à Corte seja possível, o Estado-membro envolvido deve ter reconhecido sua competência contenciosa, o que será objeto de estudo na próxima sessão.

\subsection{A Corte Interamericana de Direitos Humanos}

Órgão jurisdicional responsável pela condução de processos não resolvidos pela Comissão, com sede situada na cidade de San José, na Costa Rica, ${ }^{6}$ a Corte Interamericana de Direitos Humanos, instituída por ocasião da elaboração da própria Convenção Americana de Direitos Humanos, em 1969 (em vigor desde 1978, portanto), está prevista no art. 33 da CADH, sendo organizada nos termos dos arts. 52 a 60 do mesmo diploma normativo internacional.

Para proporcionar uma visão geral de seus elementos constitutivos, a exemplo da breve explanação empregada para descrever a Comissão Interamericana de Direitos Humanos, mister se faz reproduzir alguns dos artigos que ditam sua estrutura normativa, em especial os arts. 52,54 e 57 da Convenção Americana sobre Direitos Humanos (1969), in verbis:

\footnotetext{
6 "La Asamblea General de la OEA, el 1 de julio de 1978, recomendó aprobar el ofrecimiento formal del Gobierno de Costa Rica para que la sede de la Corte se estableciera en ese país. Esta decisión fue ratificada después por los Estados Partes en la Convención durante el Sexto Período Extraordinario de Sesiones de la Asamblea General, celebrado en noviembre de 1978. La ceremonia de instalación de la Corte se realizó en San José el 3 de septiembre de 1979." (CORTE INTERAMERICANA DE DERECHOS HUMANOS. História de la Corte IDH. Disponível em: $<$ http://www.corteidh.or.cr/index.php/es/acerca-de/historia-de-la-corteidh>. Acesso em: 24 jan. 2016.
} 


\section{Artigo 52}

1. A Corte compor-se-á de sete juízes, nacionais dos Estados membros da Organização, eleitos a título pessoal dentre juristas da mais alta autoridade moral, de reconhecida competência em matéria de direitos humanos, que reúnam as condições requeridas para o exercício das mais elevadas funções judiciais, de acordo com a lei do Estado do qual sejam nacionais, ou do Estado que os propuser como candidatos. (...)

\section{Artigo 54}

Os juízes da Corte serão eleitos por um período de seis anos e só poderão ser reeleitos uma vez. O mandato de três anos dos juízes designados na primeira eleição expirará ao cabo de três anos. Imediatamente depois da referida eleição, determinar-se-ão por sorteio, na Assembléia Geral, os nomes desses três juízes. (...)

\section{Artigo 57}

A Comissão comparecerá em todos os casos perante a Corte.

Sua jurisdição, por outro lado, está definida nos arts. 61 a 65 da Convenção, ocasião em que - legislador fez exsurgir sua dupla finalidade para o sistema interamericano: a competência contenciosa e consultiva.

Antes, porém, de explicitar a natureza dúplice da Corte em relação ao método de provocação dos expedientes a serem decididos, importante consignar que o art. 62 da $\mathrm{CADH}$ trouxe cláusula facultativa para os Estados que optassem por ratificar o édito em comento.

Trata-se da necessidade de declaração expressa, formulada pelo Estado, reconhecendo a jurisdição da Corte Interamericana de Direitos Humanos.

Acerca do tema, note-se que o Brasil formalmente manifestou a aceitação da aludida competência obrigatória da Corte em 10 de dezembro de 1998, após a tramitação do Decreto Legislativo o 89 , de 3 de dezembro do mesmo ano, aprovado por unanimidade no Congresso Nacional. O reconhecimento, assim, foi posteriormente objeto do Decreto ํㅜ 4.463/2002, submetido com reserva de reciprocidade e retroativo àquele 10 de dezembro de 1998 (BRASIL, 2002).

A medida foi considerada salutar e indispensável à consagração do sistema de defesa dos direitos humanos. Antônio Augusto Cançado Trindade (1998), por ocasião da aprovação manifestada pelo Congresso, assim ponderou sobre o assunto:

A decisão do Brasil de aceitação da competência contenciosa da Corte Interamericana de Direitos Humanos reconcilia a posição de nosso país com seu 
pensamento jurídico mais lúcido, além de congregar as instituições do poder público e as organizações não-governamentais e demais entidades da sociedade civil brasileira em torno de uma causa comum: a do alinhamento pleno e definitivo do Brasil com o movimento universal dos direitos humanos, que encontra expressão concreta na considerável evolução dos instrumentos internacionais de proteção nas cinco últimas décadas. (...)

(...) Pela iniciativa que vem de tomar, o Brasil enfim reconhece que não é razoável aceitar tão-somente as normas substantivas dos tratados de direitos humanos, fazendo abstração dos mecanismos processuais para a vindicação e salvaguarda de tais direitos. Umas e outros encontram-se indissoluvelmente interligados, sendo a via jurisdicional, de base convencional, a forma mais evoluída de proteção internacional dos direitos humanos.

Portanto, resta atendida a condição expressa no art. 62 da Convenção Americana de Direitos Humanos pelo Brasil, de maneira a possibilitar o cotejo entre os julgados da Corte e os precedentes exarados pelo Supremo Tribunal Federal, objeto principal do presente estudo no próximo capítulo.

E ainda, diferentemente da previsão de acesso direto - pelos que buscam amparo da justiça internacional contra arbitrariedades - à Comissão Interamericana de Direitos Humanos, tal prerrogativa não subsiste no que tange à Corte, por expressa vedação contida no art. 61 da Convenção, ${ }^{7}$ não obstante importantes reformas ocorridas junto ao Regulamento da Corte desde 2001, permitindo que vítimas, familiares ou representantes legais apresentem argumentos e documentos em todas as fases do processo admitido na Corte (PIOVESAN, 2014, p. 152).

Prosseguindo, há, assim, a prerrogativa contenciosa da Corte Interamericana, para o fim de julgar litígios estabelecidos a partir de denúncias de violação, por determinado Estado signatário, dos direitos humanos previstos na Convenção.

Seus julgados detêm caráter jurídico vinculante, obrigando o Estado violador à promoção de medidas para cessar a afronta à Convenção, bem como ao pagamento de indenização à vítima. Em tais casos de compensação pecuniária, a decisão proferida pela Corte é suficiente para gerar título executivo judicial (PIOVESAN, 2014, p. 153), formado a partir da combinação sistemática de dispositivos legais de direito interno para com os preceitos normativos constantes do tratado internacional subscrito pelo Estado-membro.

Nessa direção, oportuno registrar a significativa contribuição da Corte quanto ao alcance das reparações impostas aos Estados-membros da CADH. Afinal, para além do pagamento de indenizações às vítimas, Estados são compelidos a dedicar-se a reformas legislativas que, ultimadas, prevejam condutas de acordo com as premissas humanitárias defendidas na Convenção, ou ainda,

\footnotetext{
7 "Artigo 61. 1. Somente os Estados Partes e a Comissão têm direito de submeter caso à decisão da Corte. (...)" (COMISSÃO INTERAMERICANA DE DIREITOS HUMANOS. Convenção americana sobre direitos humanos. Disponível em: $<$ https://www.cidh.oas.org/basicos/portugues/c.convencao_americana.htm>. Acesso em: 24 jan. 2016.)
} 
são incumbidos até mesmo de modificar entendimentos jurisprudenciais exarados equivocadamente por determinado Tribunal interno, quando da resolução de conflito que trate de direitos humanos. ${ }^{8}$

Quanto ao acompanhamento das decisões proferidas pela Comissão e pela Corte Interamericana e sua observância pelos Estados-membros, o art. 65 da $\mathrm{CADH}^{9}$ dispõe, de maneira periférica, acerca de um relatório, elaborado pela Corte, em que são elencadas suas atividades profissionais em um dado lapso temporal.

Este documento teria a missão de revelar o cumprimento e o descumprimento das decisões da Corte e, com isso, submeter os Estados infratores aos rigores da legislação ao qual se submeteram. Porém, é cediço que, neste ponto, carece o sistema regional de aparato efetivo, capaz de fiscalizar com eficiência eventuais desmandos ocorridos no âmbito interno integrantes da CADH.

Na visão de Antônio Augusto Cançado Trindade e Manuel E. Ventura Robles (2003), embora os Estados, em geral, atendam as condenações pecuniárias em favor das vítimas de atos estatais, não há correspondência para com outras medidas relacionadas a determinações de outra natureza, a exemplo de investigações aprofundadas e a identificação/responsabilização de agentes pela ilegalidade que se apurou, o que fragilizaria o sistema.

Para tais autores, a solução passaria pelo estabelecimento de posturas positivas em todos os Estados-membros da CADH, realizando-se um monitoramento internacional permanente, englobando medidas de prevenção e controle (TRINDADE; ROBLES, 2003, p. 294), metodologia interessante e com a qual se compactua.

A respeito da competência consultiva da Corte, as opiniões consultivas exaradas pela Corte podem ter, em sua gênese, requerimento formulado por qualquer membro da Organização dos Estados Americanos - OEA.

A motivação encontrada para solicitar um parecer da Corte pode estar relacionada à interpretação de determinada cláusula da Convenção, sem olvidar de quaisquer outros tratados que versem sobre a proteção dos direitos humanos para Estados americanos.

Antonio Celso Alves Pereira (2014, p. 21-36), ao desenvolver estudo sobre o assunto, concluiu acertadamente que "As opiniões consultivas emitidas pela Corte Interamericana de Direitos Humanos são fontes jurisprudenciais de suma importância para evolução do Direito Internacional dos Direitos Humanos", consubstanciando-se em importante método de uniformização de posicionamentos e pacificação de conflitos.

\footnotetext{
${ }^{8}$ Sobre o assunto, cf. PASQUALUCCI, 2003, p. 289-290.

9 "Artigo 65. A Corte submeterá à consideração da Assembléia Geral da Organização, em cada período ordinário de sessões, um relatório sobre suas atividades no ano anterior. De maneira especial, e com as recomendações pertinentes, indicará os casos em que um Estado não tenha dado cumprimento as suas sentenças." (COMISSÃO INTERAMERICANA DE DIREITOS HUMANOS. Convenção americana sobre direitos humanos. Disponível em: $<$ https://www.cidh.oas.org/basicos/portugues/c.convencao_americana.htm>. Acesso em: 24 jan. 2016.)
} 
Entretanto, conforme preleciona Antônio Augusto Cançado Trindade (1996), mesmo que detenham status de fonte jurisprudencial necessária à consagração dos direitos humanos, as Cortes regionais (Interamericana, Europeia e Africana) não podem atuar como substitutos da jurisdição interna, ou ainda, como instância recursal ordinária das decisões com as quais uma das partes manifesta irresignação, não obstante possam tais atos internos serem confrontados para com disposições internacionalmente reconhecidas em prol dos direitos humanos.

Enfim, constata-se que o sistema de proteção dos direitos humanos possui índole multinível, oferecendo garantias desde o âmbito global (Declaração Universal dos Direitos Humanos, p. ex.), até o nível regional (Convenção Americana de Direitos Humanos), ambos existentes para além da proteção local, garantida pelo arcabouço jurídico-constitucional interno dos Estados-partes.

Tal sistema de proteção garante à Corte a prerrogativa de efetuar a análise da compatibilidade de dispositivos legais previstos na legislação local em relação aos parâmetros protetivos regionais interamericanos, em uma clara expressão do "controle de convencionalidade", o qual bem traduz o empoderamento do sistema de proteção dos direitos humanos e o diálogo que proporciona entre as instâncias já referidas (PIOVESAN, 2014, p. 148).

O controle de convencionalidade revela a emergência de um novo paradigma jurídico pautado no human rights approach, em que (i) cláusulas constitucionais abertas permitem a integração entre os planos nacional e internacional, em termos de direitos humanos - caso da expansão do bloco de constitucionalidade, previsto, v. g., no art. $5^{\circ}, \S 2^{\circ}$, da Constituição brasileira -; e (ii) regras de hermenêutica estão embasadas no princípio pro persona, fazendo prevalecer a norma mais benéfica ao indivíduo, seja na modalidade de controle de convencionalidade difuso (juízes membros de Tribunais internos, ao observarem desde o início as prerrogativas internacionais (MAC-GREGOR, 2011, p. 340) ou concentrado - exercido pela própria Corte Interamericana, em última instância (PIOVESAN, 2015, p. 126-134).

Passa-se, assim, ao exame da jurisprudência interamericana em matéria de direito à saúde.

\section{A JURISPRUDÊNCIA INTERAMERICANA EM MATÉRIA DE DIREITO À SAÚDE}

Importa neste tópico avaliar a jurisprudência interamericana em matéria de direito à sáude, com destaque às decisões proferidas tanto pela Comissão, quanto pela Corte Interamericana de Direitos Humanos.

Desde logo, observe-se que, por vezes, a tutela do direito à saúde se dá no âmbito da Comissão e Corte Interamericana de Direitos Humanos de maneira indireta ou reflexa, mediante a proteção de direitos civis e políticos. ${ }^{10}$

10 Nesse sentido: "Quando, devido a alguns dos obstáculos mencionados, resulte impossível a tutela
judicial direta de um direito social, existem estratégias para protegê-lo indiretamente, forçando a sua
consideração em juízo através de várias vias que desenvolveremos em seguida. Trata-se de
aproveitar as possibilidades de justiciabilidade e os mecanismos de tutela fornecidos por outros 
Para Edilene Mendonça Bernardes e Carla Aparecida Arena Ventura (2013, p. 107-128), "a temática de saúde encontra na Convenção Americana sobre Direitos Humanos forte respaldo para análise das obrigações do Estado de respeitar os direitos (artigo 1º); o dever de adotar disposições de direito interno (artigo $2^{\circ}$ ); o direito à vida (artigo $4^{\circ}$ ); o direito à integridade pessoal (artigo $5^{\circ}$ ); as garantias judiciais (artigo $8^{\circ}$ ); o direito à indenização (artigo 10)".

Após a realização de pesquisa junto ao repositório oficial de jurisprudência e decisões diversas de ambos os órgãos de monitoramento da CADH, foram selecionados 5 (cinco) casos, sendo 3 (três) submetidos à Comissão e 2 (dois) em trâmite na Corte. Não obstante apenas duas situações de violação a direitos humanos estarem subordinadas ao órgão jurisdicional regional, válida é a menção de que os casos em trâmite perante a Comissão foram igualmente remetidos à Corte, tendo em vista o não cumprimento de todas as determinações formuladas, o que demonstra relutância dos membros da Convenção para empregar efetividade aos mandamentos substantivos.

O recorte temporal utilizado ocorreu entre os anos de 2010 e 2015, considerando restar evidenciado, já com a análise dos cases selecionados, o não atendimento de algumas das prescrições advindas da Corte e Comissão.

Não se olvide, entretanto, de um leading case acrescido ao estudo, cujos eventos se deram em momento anterior ao lapso temporal escolhido para o recorte (2006), em razão de sua emblemática importância para o Brasil, eis que se revelou a primeira condenação do país pela Corte Interamericana de Direitos Humanos.

Trata-se do caso primeiro a ser objeto de estudo, paradigmático, conhecido por "caso Ximenes Lopes vs. Brasil" (CORTE INTERAMERICANA DE DERECHOS HUMANOS).

Procedendo-se a um breve histórico da demanda, Damião Ximenes Lopes submeteu-se a tratamento psiquiátrico em instituição de saúde particular, em 01/10/1999. Ocorre que, tendo sido vítima de maus tratos e despreparo profissional, três dias depois veio a falecer tragicamente.

Indignados para com as diversas violações sofridas, relacionadas à vida, integridade física, garantias judiciais (para apuração da responsabilidade), dentre outras, seus familiares recorreram à Comissão Interamericana de Direitos Humanos, a qual, após ver naufragar seus esforços para a resolução da questão, encaminhou o feito à Corte Interamericana de Direitos Humanos.

Após o devido processo legal, decisão unânime reconheceu a responsabilidade internacional do Brasil pela violação das prerrogativas inerentes à vida e integridade pessoal, além dos direitos e garantias judiciais de seus familiares, nos termos seguintes:

direitos, de modo a permitir, por esta via, o amparo do direito social em questão" (ABRAMOVICH, 2002, p. 340). (tradução nossa) 
6. O Estado deve garantir, em um prazo razoável, que o processo interno destinado a investigar e sancionar os responsáveis pelos fatos deste caso surta seus devidos efeitos, nos termos dos parágrafos 245 a 248 da presente Sentença. 7. O Estado deve publicar, no prazo de seis meses, no Diário Oficial e em outro jornal de ampla circulação nacional, uma só vez, o Capítulo VII relativo aos fatos provados desta Sentença, sem as respectivas notas de pé de página, bem como sua parte resolutiva, nos termos do parágrafo 249 da presente Sentença. 8. O Estado deve continuar a desenvolver um programa de formação e capacitação para o pessoal médico, de psiquiatria e psicologia, de enfermagem e auxiliares de enfermagem e para todas as pessoas vinculadas ao atendimento de saúde mental, em especial sobre os princípios que devem reger o trato das pessoas portadoras de deficiência mental, conforme os padrões internacionais sobre a matéria e aqueles dispostos nesta Sentença, nos termos do parágrafo 250 da presente Sentença. 9. O Estado deve pagar em dinheiro para as senhoras Albertina Viana Lopes e Irene Ximenes Lopes Miranda, no prazo de um ano, a título de indenização por dano material, a quantia fixada nos parágrafos 225 e 226, nos termos dos parágrafos 224 a 226 da presente Sentença. 10. O Estado deve pagar em dinheiro para as senhoras Albertina Viana Lopes e Irene Ximenes Lopes Miranda e para os senhores Francisco Leopoldino Lopes e Cosme Ximenes Lopes, no prazo de um ano, a título de indenização por dano imaterial, a quantia fixada no parágrafo 238 , nos termos dos parágrafos 237 a 239 da presente Sentença. 11. O Estado deve pagar em dinheiro, no prazo de um ano, a título de custas e gastos gerados no âmbito interno e no processo internacional perante o sistema interamericano de proteção dos direitos humanos, a quantia fixada no parágrafo 253, a qual deverá ser entregue à senhora Albertina Viana Lopes, nos termos dos parágrafos 252 e 253 da presente Sentença. 12. Supervisionará o cumprimento íntegro desta Sentença e dará por concluído este caso uma vez que - Estado tenha dado cabal cumprimento ao disposto nesta Sentença. No prazo de um ano, contado a partir da notificação desta Sentença, o Estado deverá apresentar à Corte relatório sobre as medidas adotadas para o seu cumprimento. (...) (CORTE INTERAMERICANA DE DERECHOS HUMANOS).

Note-se que, para além dos danos materiais e morais reconhecidos em favor dos familiares de Damião Ximenes Lopes, a Corte assume função proativa, exarando ordens que têm por escopo a prevenção de casos futuros, reforçando o caráter vinculativo e obrigatório de seus termos em desfavor dos Estados-membros (BONTEMPO; CARVALHO, 2010, p. 123-149).

Inclusive, ressalte-se consequência benéfica extraída das lições acima contidas, qual seja a edição da Lei oㅜ 10.216, de 6 de abril de 2001 (BRASIL, 2001), que remodelou o modelo assistencial em saúde mental no Brasil.

Considerando o emblemático caso "Ximenes Lopes vs. Brasil", passa-se à análise dos demais casos:

1) Caso Suárez Peralta vs. Equador, sentença da Corte Interamericana de Direitos Humanos, de 21 de maio de 2013 (CORTE INTERAMERICANA DE DERECHOS HUMANOS, 2013). 
Melba del Carmen Suárez Peralta, em 28 de junho de 2000, acometida por fortes dores abdominais, submeteu-se a procedimento cirúrgico em hospital da rede pública, o qual se revelou inadequado, ocasionando-Ihe diversas sequelas que diminuíram sua qualidade de vida, além de revelar a falta de sistematização de procedimentos hospitalares. Além disso, houve omissão e toda sorte de empecilhos processuais, o que prejudicou ainda mais a paciente.

Nesse caso, a Corte, após discorrer exaustivamente acerca da metodologia empregada para a resolução de casos como o ora analisado, proferiu sua sentença nos termos seguintes:

6. Esta Sentencia constituye per se una forma de reparación. 7. El Estado debe realizar las publicaciones que se indican en el párrafo 189 del presente Fallo, en el plazo de 6 meses contado a partir de la notificación de la Sentencia. 8. El Estado debe pagar las cantidades fijadas en los párrafos 184, 214 y 220 de la presente Sentencia por concepto de atención médica futura de la señora Suarez Peralta, indemnizaciones por daño material e inmaterial, reintegro de costas y gastos en el plazo de un año, contado a partir de la notificación de la misma. Asimismo, el Estado debe pagar las cantidades fijadas en el párrafo 224 de la presente Sentencia por reintegro al Fondo de Asistencia Legal de Víctimas en el plazo de noventa días. 9. El Estado debe, dentro del plazo de un año contado a partir de la notificación de esta Sentencia, rendir al Tribunal un informe sobre las medidas adoptadas para cumplir con la misma. (... $)^{11}$

Na hipótese, a Corte reconheceu a violação expressa, pelo Estado do Equador, dos arts. 8.1 e 25.1 da Convenção Americana dos Direitos Humanos, combinado com o art. 1.1, em desfavor de Melba del Carmen e sua genitora, Melba Peralta Mendoza.

2) Caso n. 12.354, Pueblos Indígenas Kuna de Madungandí y Emberá de Bayano y sus membros vs. Panamá, Comissão Interamericana de Direitos Humanos (COMISIÓN INTERAMERICANA DE DERECHOS HUMANOS, 2012).

O caso envolve os povos indígenas supramencionados, que se viram obrigados a deixar suas terras ancestrais em razão da construção de complexo hidrelétrico durante os anos de 1972 e 1976, sendo compelidos pelo Estado-membro do Panamá a habitar nova localidade, além de aceitar indenização pecuniária em troca da destruição de seus lares.

\footnotetext{
11 “6. Este julgamento se dá sob a forma de reparação. 7. O Estado deve realizar as publicações indicadas no parágrafo 189 da presente decisão, no prazo de 6 meses contado a partir da notificação da sentença. 8. 0 Estado deve pagar as quantidades fixadas nos parágrafos 184, 214 e 220 da presente sentença, em relação à atenção médica futura da senhora Suarez Peralta, indenizações por dano material e imaterial, reembolso de custas e despesas, no prazo de um ano, contado a partir da notificação da mesma. E ainda, o Estado deve pagar os montantes estabelecidos no parágrafo 224 da presente sentença, para reembolso ao Fundo de Assistência Legal de Vítimas no prazo de noventa dias. 9. O Estado deve, dentro do prazo de um ano, contado a partir da notificação da presente sentença, entregar ao Tribunal um relatório sobre as medidas adotadas para cumprir com a decisão. (....)" (tradução nossa)
} 
O feito fora cuidadosamente instruído, sobrevindo recomendação da Comissão Interamericana nos seguintes termos:

A COMISSÃO INTERAMERICANA DE DIREITOS HUMANOS RECOMENDA AO ESTADO DO PANAMÁ: 1. Concluir prontamente o processo de formalização, delimitação e demarcação física dos territórios dos povos e de seus membros, levando em consideração as normas interamericanas assinaladas nesse relatório. 2. Cumprir com a obrigação de outorgar aos dois povos e aos seus membros uma rápida e justa indenização pelo deslocamento, reassentamento e inundação de seus territórios ancestrais, cujo montante adequado seja determinado através de um processo que assegure sua participação, de acordo com seu direito consuetudinário, valores, usos e costumes. 3. Adotar as medidas necessárias para proteger efetivamente o território dos povos Kuna de Madungandí e Emberá del Bavano, com o objetivo de lhes garantir sua sobrevivência física e cultural, assim como o desenvolvimento e continuidade de sua cosmovisão, para que possam continuar vivendo seu modo de vida tradicional e conservar sua identidade cultural, estrutura social, sistema econômico, costumes, crenças, tradições distintivas e sistema de justiça. Ademais, adotar as medidas necessárias para que seja assegurado aos povos Kuna de Madungandí e Emberá del Bavano o acesso a programas de saúde e de educação culturalmente pertinentes. 4. Impedir a entrada ilegal de pessoas não indígenas nos territórios dos povos Kuna de Madungandí e Emberá del Bayano e transferir os atuais colonos ocupantes para territórios que não pertençam aos povos indígenas. Além disso, garantir o consentimento livre, prévio e informado dos povos sobre os planos, programas e projetos que se pretende desenvolver em seus territórios. 5. Estabelecer um recurso adequado e eficaz que tutele o direito dos povos indígenas do Panamá a reivindicar e retornar a seus territórios tradicionais, assim como a proteger seus territórios e recursos naturais diante de terceiros, incluindo o respeito ao direito dos povos indígenas a aplicar suas normas consuetudinárias através de seus sistemas de justiça. 6. Reparar no âmbito coletivo e individual as consequências às violações dos direitos humanos determinadas no Relatório de Mérito. Em especial, reparar a ausência de proteção dos territórios ancestrais dos povos Kuna de Madungandí e Emberá del Bayano, a falta de resposta eficaz e oportuna por parte das autoridades e o tratamento discriminatório ao qual foram submetidos. 7 . Adotar as medidas necessárias para evitar que no futuro sejam produzidos fatos similares, conforme o dever de prevenção e de garantia dos direitos fundamentais reconhecidos na Convenção Americana. (CONSELHO NACIONAL DE JUSTIÇA, 2014, p. 6)

Na hipótese, não tendo sido constatado o cumprimento pelo Estado do Panamá de todas as recomendações efetuadas, o feito foi encaminhado à Corte, para análise e posterior julgamento. Porém, restou determinado que deve o Panamá desenvolver programas de saúde pública para atender os indígenas, garantindo-lhes dignidade.

3) Caso Maira Inés Chinchilla Sandoval y otros vs. Guatemala, Comissão Interamericana de Direitos Humanos (COMISIÓN INTERAMERICANA DE DERECHOS HUMANOS, 2014). 
María Inés Chinchilla Sandoval foi uma vítima do sistema carcerário guatemalteco. No processo submetido à Comissão, restou demonstrado que, embora o Estado tivesse conhecimento do estado de saúde debilitado da vítima, a qual se encontrava sob custódia em razão do cometimento dos crimes de furto qualificado e homicídio, não providenciou atendimento médico adequado, o que se revelou determinante para a sua morte. A recomendação da Comissão, neste caso, contém os seguintes termos:

1. Reparar integralmente las violaciones de derechos humanos declaradas en el presente informe, incluyendo tanto en el aspecto material como moral. 2. Desarrollar y completar una investigación imparcial, completa y efectiva, de manera expedita, con el objeto establecer las responsabilidades penales o de otra índole por las violaciones establecidas en el presente informe. 3. Adoptar medidas de no repetición que incluyan: i) la garantía del acceso médico adecuado y oportuno en el Centro de Orientación Femenino; ii) la garantía de las condiciones adecuadas de privación de libertad para las personas con discapacidad en el Centro de Orientación Femenino, conforme a los estándares descritos en el presente informe; iii) el fortalecimiento institucional y la capacitación de las autoridades judiciales a cargo de la ejecución de las penas, a fin de que cumplan efectivamente con su rol de garantes de los derechos de las personas privadas de libertad; y iv) la regulación de un recurso judicial rápido y efectivo que permita obtener protección a los derechos a la vida e integridad personal, frente a las necesidades de salud de las personas privadas de libertad. ${ }^{12}$

Entendeu a Comissão que María Inés e seus familiares foram vítimas do descaso estatal, seja no tocante à assistência médica deficitária para a vítima, seja em relação à falta com a verdade nas investigações sobre as circunstâncias de sua morte.

4) Caso 12.655: I. vs. Bolívia, Comissão Interamericana de Direitos Humanos (COMISIÓN INTERAMERICANA DE DERECHOS HUMANOS, 2015).

O caso em comento trata de uma esterilização forçada realizada em I.V. - procedimento cirúrgico realizado sem o consentimento da cidadã boliviana.

\footnotetext{
12 "1. Reparar integralmente as violações de direitos humanos declaradas no presente relatório, incluindo os aspectos material e moral. 2. Desenvolver e concluir uma investigação imparcial, completa e efetiva, de maneira célere, com o objetivo de estabelecer a responsabilidade penal ou de outra natureza, pelas violações estabelecidas no presente relatório. 3. Adotar medidas preventivas que incluam: (i) a garantia de acesso médico adequado e oportuno no Centro de Orientação Feminina [centro de cumprimento de penas privativas de liberdade]; (ii) assegurar condições adequadas de privação de liberdade para pessoas com deficiência no Centro de Orientação Feminina, conforme os padrões descritos no presente relatório; (iii) o fortalecimento institucional e a capacitação das autoridades judiciais responsáveis pela execução das penas, a fim de que cumpram efetivamente com seu papel de garantes dos direitos das pessoas privadas de liberdade; e (iv) a regulamentação de recurso judicial rápido e efetivo, que permita obter proteção ao direito à vida e à integridade física frente às necessidades de saúde das pessoas privadas de liberdade." (tradução nossa)
} 
Após reconhecer a responsabilidade internacional do Estado da Bolívia, a Comissão editou as seguintes recomendações:

1. Reparar integralmente a I.V. por las violaciones de derechos humanos establecidas en el informe, tomando en consideración su perspectiva y sus necesidades, incluida la compensación de los daños materiales y morales sufridos. 2. Proporcionar a I.V. un tratamiento médico de alta calidad, individualizado según sus necesidades y adecuado para tratar las patologías que padece. 3. Investigar los hechos relativos a la esterilización no consentida de I.V. y establecer las responsabilidades y sanciones que resulten procedentes. 4. Adoptar las medidas de no repetición necesarias para evitar que en el futuro se produzcan hechos similares, y en particular, revisar las políticas y prácticas aplicadas en todos los hospitales respecto de la obtención de consentimiento informado de las y los pacientes. 5. Adoptar legislación, políticas públicas, programas y directivas para asegurar que se respete el derecho de todas las personas a ser informadas y orientadas en materia de salud, y a no ser sometidas a intervenciones 0 tratamientos sin contar con su consentimiento informado, cuando éste resulte aplicable. Tales medidas deben tener especial consideración de las necesidades particulares de las personas que se encuentran en una situación de vulnerabilidad por la intersección de factores tales como su sexo, raza, posición económica, o condición de migrante, entre otros. 6. Investigar las falencias en las prácticas del Poder Judicial y órganos auxiliares que permiten las dilaciones excesivas en los procedimientos judiciales y adoptar las medidas que sean necesarias para garantizar el efectivo acceso a la justicia a través del debido proceso y una administración de justicia expedita y eficiente. ${ }^{13}$

\section{CONSIDERAÇÕES FINAIS}

As recomendações da Comissão e as sentenças da Corte Interamericana em matéria da proteção ao direito à saúde compõem, assim, um corpus juris interamericano. Ao endossar a responsabilidade internacional do Estado na necessária observância de parâmetros protetivos mínimos em matéria de direito à saúde, destaca-se o dever do Estado em adotar relevantes medidas para a plena implementação do direito à saúde, compreendendo:

\footnotetext{
13 "1. Reparar integralmente I.V. pelas violações aos direitos humanos estabelecidas no relatório, considerando sua perspectiva e suas necessidades, incluída a compensação pelos danos materiais e morais sofridos. 2 . Proporcionar a I.V. um tratamento médico de alta qualidade, individualizado segundo suas necessidades e adequado para tratar as patologias que padece. 3 . Investigar os fatos relativos à esterilização não consentida de I.V. e estabelecer as responsabilidades e sanções que resultem procedentes. 4. Adotar as medidas preventivas necessárias para evitar que no futuro ocorram fatos semelhantes e, em particular, revisar as políticas e práticas aplicadas em todos os hospitais a respeito da obtenção de consentimento informado dos pacientes. 5. Aprovar legislação, políticas públicas, programas e diretrizes para assegurar que se respeite o direito de todas as pessoas de serem informadas e orientadas em matéria de saúde, e a não serem submetidas a intervenções ou tratamentos sem contar com seu consentimento expresso, quando aplicável. Tais medidas devem ter especial consideração pelas necessidades particulares das pessoas que se encontram em uma situação de vulnerabilidade pela interseção de fatores tais como sexo, raça, posição econômica, condição de migrante, entre outros. 6 . Investigar as falhas nas práticas do Poder Judiciário e órgãos auxiliares que permitem as dilações excessivas nos procedimentos judiciais e adotar as medidas que sejam necessárias para garantir o acesso efetivo à justiça através do devido processo e uma administração judicial rápida e eficiente." (tradução nossa)
} 
a) a formação de políticas públicas direcionadas, capazes de atender parcela da população acometida por enfermidades específicas e garantir, com isso, a qualidade e a segurança do atendimento ( $v$. g. caso Ximenes Lopes vs. Brasil);

b) a maximização do acesso à saúde pública e, ao mesmo tempo, a garantia de universalidade no atendimento eficiente, respeitando-se as diferenças culturais dos destinatários das ações de saúde ( $v$. g. caso Pueblos Indígenas Kuna de Madungandí y Emberá de Bayano y sus miembros, Panamá);

c) a implementação de medidas de saúde que alcancem especificamente os estabelecimentos de custódia, para que assegurem a promoção efetiva da saúde coletiva ( $v$. g. caso María Inés Chinchilla Sandoval);

d) a elaboração de legislação e programas governamentais que conscientizem os cidadãos a respeito de seus direitos sociais, para que tomem decisões informados de todas as consequências das intervenções cirúrgicas, respeitada a diversidade cultural e a capacidade intelectual de cada indivíduo (v. g. caso I.V.);

e) a investigação de falhas no aparato judicial e reformá-las, a fim de evitar dilações excessivas e prestigiar o princípio do devido processo legal e empregar eficiência ao Judiciário ( $v$. $g$. caso I.V.);

f) a promoção e disseminação da concepção contemporânea do direito à saúde, entendido como o direito humano ao desfrute do mais elevado nível possível de saúde física e mental (escopo de todos os casos citados).

Observe-se que a pavimentação de um "corpus juris interamericano" em matéria do direito à saúde revela, a um só tempo, a louvável atuação do sistema interamericano de proteção dos direitos humanos, capaz de responder ao arbítrio e às graves violações de direitos, demandando dos Estados o cumprimento de deveres afetos a direitos dos indivíduos, fomentando avanços e detendo retrocessos em matéria de direitos.

Gradativamente, vislumbra-se o impacto emancipatório e transformador da jurisprudência interamericana no âmbito dos Estados, propiciando a adoção de novos marcos jurídicos e a formulação de políticas públicas para a efetiva realização de direitos, a compreender a proteção, a defesa e a promoção dos direitos humanos, em particular do direito à saúde.

Por fim, paulatinamente fortalece-se a criação de um constitucionalismo regional - um ius commune social -, bem como a emergência de um Estado de Direito Internacional, pautado pelo primado da legalidade, por uma expansiva institucionalidade baseada em instrumentos e órgãos internacionais visando à prevalência da dignidade humana, com ênfase na proteção dos direitos dos mais vulneráveis em nossa região.

\section{REFERÊNCIAS}

ABRAMOVICH, Victor; COURTIS, Christian. Los derechos sociales como derechos exigibles. Madri: Trotta, 2002.

BERNARDES, Edilene Mendonça; Ventura, Carla Aparecida Arena. A Comissão Interamericana de Direitos Humanos e os casos de violação dos direitos humanos relacionados à saúde envolvendo o 
Brasil no período 2003-2010. Revista de Direitos Fundamentais e Democracia, Curitiba, v. 13, n. 13, p. 107-128, jan./jun. 2013.

BONTEMPO, Alessandra Gotti; Carvalho, Patrícia Luciane. Direito à saúde: uma análise da jurisprudência nacional e internacional. In: IKAWA, Daniela; PIOVESAN, Flávia; FACHIN, Melina Girardi (coords.). Direitos humanos na ordem contemporânea: proteção nacional, regional e global. Vol. III. Curitiba: Juruá, 2010. p. 123-149.

BRASIL. Decreto no 4.462, de 8 de novembro de 2002 . Disponível em: <http://www.planalto.gov.br/ccivil_03/decreto/2002/d4463.htm>. Acesso em: 20 jan. 2016.

Lei no 10.216, de 6 de abril de 2001 . Disponível em:

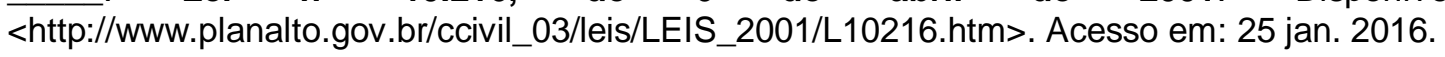

COMISIÓN INTERAMERICANA DE DERECHOS HUMANOS. I.V., Bolívia. Disponível em: <http://www.oas.org/es/cidh/decisiones/corte/2015/12655FondoEs.pdf>. Acesso em: 6 abr. 2017.

María Inés Chinchilla Sandoval y otros, Guatemala. Disponível em: $\overline{<h t t p: / / w w w . o a s . o r g / e s / c i d h / d e c i s i o n e s / c o r t e / 12739 F o n d o E s . p d f>. ~ A c e s s o ~ e m: ~} 25$ jan. 2016.

Pueblos indígenas Kuna de Madungandí y Emberá de Bayano y sus miembros, Panamá. Disponível em: <http://www.oas.org/es/cidh/decisiones/corte/12.354FondoEsp.pdf>. Acesso em: 25 jan. 2016. $\begin{aligned} & \text { COMISSÃO INTERAMERICANA DE DIREITOS HUMANOS. Convenção americana sobre direitos } \\ & \text { humanos. }\end{aligned}$
em: $<$ https://www.cidh.oas.org/basicos/portugues/c.convencao_americana.htm>. Acesso em: 24 jan. 2016.

Protocolo adicional à Convenção Americana sobre direitos humanos em matéria de direitos econômicos, sociais e culturais, "Protocolo de San Salvador". Disponível em:<http://www.cidh.org/Basicos/Portugues/e.Protocolo_de_San_Salvador.htm>. Acesso em: 19 jan. 2016.

COMPARATO, Fábio Konder. A afirmação histórica dos direitos humanos. 8. ed. São Paulo: Saraiva, 2013.

CONSELHO NACIONAL DE JUSTIÇA. Corte Interamericana de Direitos Humanos: sentenças por ano. 2014. Disponível em: <http://www.cnj.jus.br/poder-judiciario/relacoes-internacionais/corteinteramericana-de-direitos-humanos-corte-idh/sentencas>. Acesso em: 6 abr. 2017.

CORTE INTERAMERICANA DE DERECHOS HUMANOS. História de la Corte IDH. Disponível em: <http://www.corteidh.or.cr/index.php/es/acerca-de/historia-de-la-corteidh>. Acesso em: 24 jan. 2016.

2016.

Suárez Peralta vs. Ecuador. Disponível em: <http://www.corteidh.or.cr>. Acesso em: 24 jan. 2016.

Ximenes Lopes vs. Brasil. Disponível em: <http://www.corteidh.or.cr>. Acesso em: 24 jan.

HEINTZE, Hans-Joachim. Capítulo 1: os direitos humanos como matéria do direito internacional público. In: PETERKE, Sven (Coord.). Manual prático de direitos humanos internacionais. Brasília: ESMPU, 2010.

MAC-GREGOR, Eduardo Ferrer. Interpretación conforme y control difuso de convencionalidad: el nuevo paradigma para el juez mexicano. Disponível em: $<$ http://www.corteidh.or.cr/tablas/r29018.pdf>. Acesso em: 24 jan. 2016. 
ORGANIZAÇÃO DOS ESTADOS AMERICANOS. Comissão Interamericana de Direitos Humanos. Disponível em: <https://www.oas.org/pt/sobre/comissao_direitos_humanos.asp>. Acesso em: 20 jan. 2016.

ORGANIZACIÓN DE LOS ESTADOS AMERICANOS. Convencion americana sobre derechos humanos suscrita en la conferencia especializada interamericana sobre derechos humanos. Disponível em: <http://www.oas.org/dil/esp/tratados_B32_Convencion_Americana_sobre_Derechos_Humanos.pdf>. Acesso em: 20 jan. 2016.

PASQUALUCCI, Jo M. The practice and procedure of the Inter-American Court of Human Rights. Cambridge: Cambridge University Press, 2003.

PEREIRA, Antonio Celso Alves. A Competência Consultiva da Corte Interamericana de Direitos Humanos. Revista Interdisciplinar de Direito, Juiz de Fora, v. 11, n. 11, p. 21-36, jan./dez. 2014.

PIOVESAN, Flávia. Direito internacional dos direitos humanos e a lei de anistia: o caso brasileiro. In: IKAWA, Daniela; PIOVESAN, Flávia; FACHIN, Melina Girardi (coords.). Direitos humanos na ordem contemporânea: proteção nacional, regional e global. Vol. IV. Curitiba: Juruá, 2010.

Direitos humanos e justiça internacional: um estudo comparativo dos sistemas regionais europeu, interamericano e africano. 5. ed. rev. amp. e atual. São Paulo: Saraiva, 2014.

Direitos humanos e o direito constitucional internacional. 14. ed. rev. e atual. São Paulo: Saraiva, 2013.

Sistema interamericano de direitos humanos: impacto transformador, diálogos jurisdicionais e os desafios da reforma. Revista de Estudos Constitucionais, Hermenêutica e Teoria do Direito RECHTD, São Leopoldo, v. 6, n. 2, p. 142-154, jul./set. 2014.

Temas de direitos humanos. 8. ed. São Paulo: Saraiva, 2015.

QUIROGA, Cecilia Medina. The battle of human rights: gross, systematic violations and the InterAmerican System. Dordrecht: Martinus Nijhoff Publishers, 1988.

RUSSOMANO, Gilda Maciel Corrêa Meyer. Direitos humanos. 2. ed. Curitiba: Juruá, 2001.

TRINDADE, Antônio Augusto Cançado. Direito internacional e direito interno: sua interação na proteção dos direitos humanos. Disponível em: <http://www.pge.sp.gov.br/centrodeestudos/bibliotecavirtual/instrumentos/introd.htm>. Acesso em: 24 jan. 2016.

O Brasil e a Corte Interamericana de Direitos Humanos. Disponível em: $<\mathrm{http}: / /$ www.dhnet.org.br/direitos/militantes/cancadotrindade/cancado_oea.html>. Acesso em: 24 jan. 2016.

; ROBLES, Manuel E. Ventura. El futuro de la Corte Interamericana de Derechos Humanos. San José: Corte Interamericana de Derechos Humanos, 2003.

\section{COMO CITAR ESSE DOCUMENTO:}

PIOVESAN, Flavia; DE FREITAS, Daniel Castanha. O pacto de San José da Costa Rica e a jurisprudência interamericana em matéria de direito à saúde. Revista do Direito, Santa Cruz do Sul, v. 1, n. 54, p. 205-225, jun. 2018. ISSN 1982-9957. Disponível em: $<$ https://online.unisc.br/seer/index.php/direito/article/view/11843>. Acesso em: doi:http://dx.doi.org/10.17058/rdunisc.v1i54.11843. 